\title{
Evaluation of indoor temperature for various building envelopes damaged
}

\author{
Viktor Petrenko, ${ }^{1,}$, Kostiantyn Dikarev ${ }^{1}$, Denys Volchok $^{1}$ and Oleksandra Kuzmenko ${ }^{1}$ \\ ${ }^{1}$ Prydniprovska State Academy of Civil Engineering and Architecture, 49000, 24-A Chernishevskogo str., Dnipro, Ukraine
}

\begin{abstract}
The purpose of this paper is to represent inner air temperature calculation algorithm provided that interior space is formed by several building envelopes which transmit thermal losses. The chosen external wall includes an area with damaged structural layers. We examine one-dimensional thermal transfer between hot (inner) and cold (outside) space in steady-state conditions. The derived equation allows calculating the estimated inner temperature of the air taking into consideration the various combination of building envelopes on condition that one of them is damaged.
\end{abstract}

\section{Introduction}

The problem is to analyze the process of microclimate formation considering variable properties of building envelopes with damaged zone.

Analysis of previous studies shows the engineering solutions based on one-dimensional thermal transfer in steady-state conditions [1, 2]. However, there are no investigations devoted to the estimation of indoor air temperature under the assumption that building envelope contains the damaged area.

Some investigations $[3,4,5,6,7,8]$ are focused on the problem of microclimate parameters evaluation in old buildings with visibly damaged zones on building envelopes. Others refer to the problem of buildings envelope modernization but generally, they oriented to the choice of convenient technical solution for building reconstruction and analysis of thermal insulation impact on microclimate $[9,10,11]$.

The problem of indoor temperature determination for various building envelopes on condition that one of them (external wall) contains damaged zone with fractured structural layers leads us to the following tasks:

- to specify the initial data of the problem concerned;

- to derive a mathematical expression for inner air temperature determination provided that one of considered building envelopes (the external wall) is damaged by a certain area of erosion;

- to calculate and analyze the results of estimation for a particular case.

- to generalize an analytic expression;

- to carry out a numerical modeling using ELCUT software.

\section{Initial data}

Previous investigations [12, 13] allowed us to define initial data and boundary conditions for inner air temperature determination in case of the only heat transfer through an external wall with damaged zones. Analytic determination of indoor temperature for various building envelopes on condition that one of them (external wall) contains damaged zone with fractured structural layers requires the following assumptions:

- we examine plane wall, window, floor slab or roof slab containing several construction layers with different thicknesses $\delta_{1,2 \ldots n}, \mathrm{~mm}$, this solid is infinite in $y$ and $z$ direction $\left(\frac{\partial t}{\partial y}=\frac{\partial t}{\partial z}=0\right.$ - the temperature is depending on one variable only in case of one-dimensional heat conduction)

- material properties are constant $\left(\lambda_{1,2 \ldots n}=\right.$ const, $\rho_{1,2 \ldots n}=$ const,$c_{1,2 \ldots n}=$ const $)$;

- the outside surface of the wall is exposed to ambient air with temperature $t_{\text {ext }},{ }^{o} \mathrm{C}$ for the cold season while inside surface has heating air next to it with defined interior temperature $t_{\text {int }},{ }^{o} \mathrm{C}$ according to the building standard;

- there are no time dependence of the temperatures for one-dimensional steady state heat transfer $\left(\frac{\partial t}{\partial \tau}=0\right)$;

- the coefficient of heat-transfer from warm indoor air to the wall denoted by $\alpha_{\text {int }}, \frac{W}{m^{2} \cdot K}$, from wall to cool outside ambience $-\alpha_{\text {ext }}, \frac{W}{m^{2} \cdot K}$, (those values have no time dependence as well).

\section{Derivation of a formula}

* Corresponding author: petrenko@mail.pgasa.dp.ua 
If a study air space is limited by a combination of building envelopes (Fig. 1), we calculate an estimated inner temperature of the air taking into consideration that one of enclosing structures (external wall) contains the damaged area. Enclosing structures (with appropriate properties) of standard buildings of $70-80^{\text {th }}$ (XX century) were chosen for study.

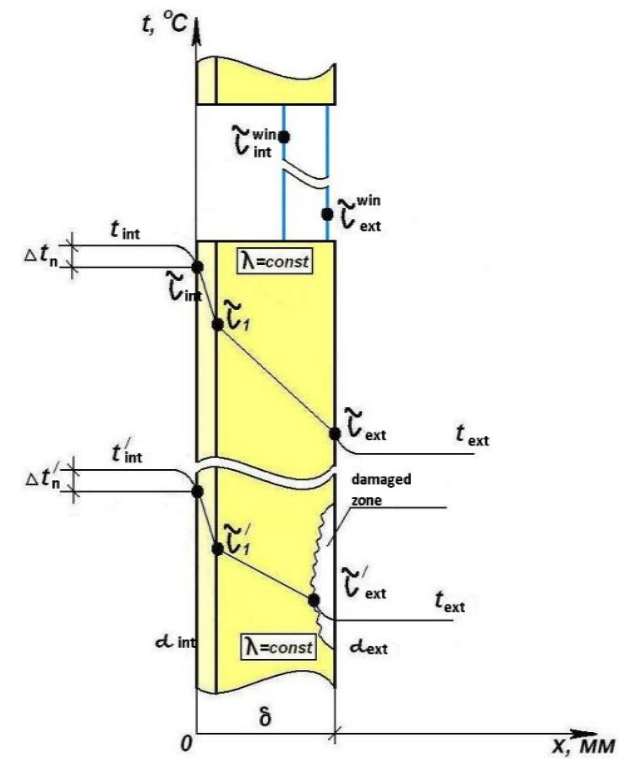

a)

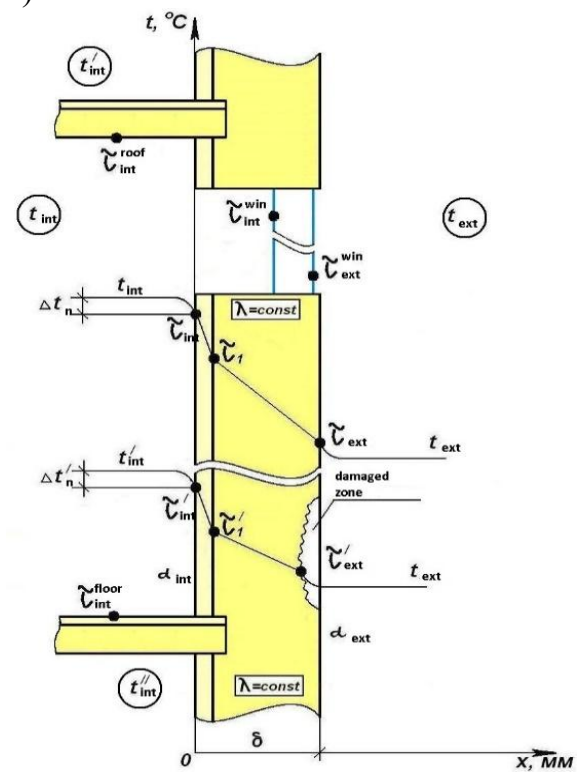

b)

Fig. 1. Variants of heat transfer through:

a) external wall with damaged zone and installed window; b) floor slab, roof slab, an external wall with damaged zone and installed window

According to the assumptions given in [13], we assume that the plane multi-layer wall contains damaged area caused by erosion. The thickness of this area $\delta_{d . z .},(\mathrm{mm})$ is ranging from 0 to $\sum \delta_{\text {wall }}$ (Fig. 1).

It is plausible to assume that the presence of damaged area on the external side of the plane wall results in the temperature change of the both inner and exterior surfaces $\left(\tau_{\text {int }}^{\prime},{ }^{o} C, \tau_{\text {ext }}^{\prime},{ }^{o} C\right)$, the same phenomenon happens to the temperature between layers $\tau_{1}^{\prime},{ }^{o} \mathrm{C}$.

Let us consider two variants of indoors with several types of building envelopes. For the first variant, we consider a room with external wall wich contains damaged zone and installed window (Fig. 1a). As for the second variant, we study a room enclosed by the floor slab, the roof slab and the external wall with damaged zone and installed window (Fig. 1b).

If we take in consideration mentioned above for the first case the heat flows through different building envelopes can be given as the following mathematical expression:

- heat flux through the plane multi-layer wall with the surface $F, m^{2}$, can be written as:

$$
Q=k_{1} \cdot F \cdot\left(t_{\text {int }}-t_{\text {ext }}\right), W
$$

$k_{1}$ - coefficient of heat transmission through the wall which does not contain damaged zones, $\frac{W}{m^{2} \cdot K}$;

$t_{\text {int }}$ - defined interior temperature, ${ }^{\circ} C$;

$t_{\text {ext }}$ - defined outside temperature for the cold season, ${ }^{\circ} \mathrm{C}$;

- the heat transfer through multi-layer damaged wall $F$, $m^{2}$, can, therefore, be given as:

$Q^{\prime}=k_{1} \cdot\left(F-F_{\text {dam }}\right) \cdot\left(t_{\text {int }}^{\prime}-t_{\text {ext }}\right)+k_{\text {dam }} \cdot F_{\text {dam }} \cdot\left(t_{\text {int }}^{\prime}-t_{\text {ext }}\right), W$

$k_{d a m}$ - the coefficient of heat transmission for the damaged wall, $\frac{W}{m^{2} \cdot K}$;

$F_{d a m}$ - area of the affected surface on the wall, $\mathrm{m}^{2}$;

$t_{\text {int }}^{\prime}$ - estimated temperature of the inner air, ${ }^{\circ} C$.

After the transformation we can obtain the following formula:

$$
Q^{\prime}=\left(k_{1} \cdot F+F_{\text {dam }} \cdot\left(k_{2}-k_{1}\right)\right) \cdot\left(t_{\text {int }}^{\prime}-t_{\text {ext }}\right), W ;
$$

- according to [14], heat flux through the window with a surface $F_{w}, m^{2}$, which is installed in the external wall without damages, can be defined as:

$$
Q_{w}=F_{w} \cdot\left(k_{w}-k_{1}\right) \cdot\left(t_{\text {int }}-t_{\text {ext }}\right), W .
$$

$k_{w}$ - the coefficient of heat transmission for the window, $\frac{W}{m^{2} \cdot K}$;

- the heat flux through the window with a surface $F_{w}$, $m^{2}$, which is installed in an external wall with damaged zone can be given as:

$$
Q_{w}^{\prime}=F_{w} \cdot\left(k_{w}-k_{\text {wall }}^{a v}\right) \cdot\left(t_{w}^{\prime}-t_{e x t}\right), W .
$$

$k_{\text {wall }}^{a v}$ - the averaged coefficient of heat transmission for the wall with damaged zone, $\frac{W}{m^{2} \cdot K}$, which can be written as: 


$$
\begin{aligned}
& k_{\text {wall }}^{a v}=\frac{k_{1} \cdot\left(F-F_{d a m}\right)+k_{d a m} \cdot F_{d a m}}{F}= \\
& =\frac{k_{1} \cdot\left(1-x_{d a m}\right) \cdot F+k_{d a m} \cdot x_{d a m} \cdot F}{F}= \\
& =k_{1}+x_{d a m} \cdot\left(k_{d a m}-k_{1}\right)
\end{aligned}
$$

$x_{d a m}$ - the part of damaged area in the whole wall and which (according to [13])can be expressed as:

$$
x_{d a m}=\frac{F_{d a m}}{F},
$$

The value of $x_{d a m}$ is ranging from 0 to 1 .

Let us suppose that the heating equipement produces the equal quantity of thermal energy whether the wall (with window) contains damaged area or not. The condition $Q=Q^{\prime}$ implies that:

$$
\begin{aligned}
& \left(k_{1} \cdot F+F_{\text {dam }} \cdot\left(k_{2}-k_{1}\right)\right) \cdot\left(t_{\text {int }}^{\prime}-t_{\text {ext }}\right)+F_{w} \cdot\left(k_{w}-k_{\text {wall }}^{a v}\right) \cdot\left(t_{w}^{\prime}-t_{\text {ext }}\right)= \\
& =k_{1} \cdot F \cdot\left(t_{\text {int }}-t_{\text {ext }}\right)+F_{w} \cdot\left(k_{w}-k_{1}\right) \cdot\left(t_{\text {int }}-t_{\text {ext }}\right)
\end{aligned}
$$

The estimated temperature of the interior air can be derivated from (8)

$t_{\mathrm{int}}^{\prime}=\frac{k_{1} \cdot F \cdot\left(t_{\mathrm{int}}-t_{e x t}\right)+F_{w} \cdot\left(k_{w}-k_{1}\right) \cdot\left(t_{\mathrm{int}}-t_{e x t}\right)}{k_{1} \cdot F+F_{\text {dam }} \cdot\left(k_{d a m}-k_{1}\right)+F_{w} \cdot\left(k_{w}-k_{d a m}^{a v}\right)}+t_{e x t},{ }^{o} C$.

Taking into consideration (7) an expression (9) can be written as:

$$
t_{\text {int }}^{\prime}=\frac{\left(k_{1} \cdot F+F_{w} \cdot\left(k_{w}-k_{1}\right)\right) \cdot\left(t_{\text {int }}-t_{\text {ext }}\right)}{k_{1} \cdot F+x_{\text {dam }} \cdot F \cdot\left(k_{\text {dam }}-k_{1}\right)+F_{w} \cdot\left(k_{w}-k_{\text {dam }}^{a v}\right)}+t_{\text {ext }},{ }^{o} C
$$

Concerning the second variant, heat flux through the building envelopes including installed window in a plane external wall with or without damaged zone can be given in the same way as for (1), (2), (3), (4). For the other building envelopes heat flux can be calculated using the following expression:

- heat flux through the floor slab with the surface $F_{\text {floor }}$, $m^{2}$, can be calculated as:

$$
Q_{\text {floor }}=k_{\text {floor }} \cdot F_{\text {floor }} \cdot\left(t_{\text {int }}-t_{\text {ext }}\right) \cdot n_{\text {floor }}, W \text {, }
$$

$k_{\text {floor }}$ - the coefficient of heat transmission for the floor slab, $\frac{W}{m^{2} \cdot K}$;

$n_{\text {floor }}$ - a coefficient which depends on the positioning of the building envelope (floor slab) against the external air;

- heat flux through the roof slab with the surface $F_{\text {roof }}$, $m^{2}$ can be written as:

$$
Q_{\text {roof }}=k_{\text {roof }} \cdot F_{\text {roof }} \cdot\left(t_{\text {int }}-t_{\text {ext }}\right) \cdot n_{\text {roof }}, W \text {, }
$$

$k_{\text {roof }}$ - the coefficient of heat transmission for the roof slab, $\frac{B m}{M^{2} \cdot K}$;

$n_{\text {roof }}$ - a coefficient which depends on the positioning of the building envelope (roof slab) against the external air;
- heat flux through the floor slab with the surface area $F_{\text {floor }}, m^{2}$ of the room enclosed by an external wall which contains damaged zone, can be represented as:

$$
Q_{\text {floor }}^{\prime}=k_{\text {floor }} \cdot F_{\text {floor }} \cdot\left(t_{\text {int }}^{\prime}-t_{\text {ext }}\right) \cdot n_{\text {floor }}, W \text {; }
$$

- heat flux through the roof slab with the surface area $F_{\text {roof }}, m^{2}$, of the room enclosed by an external wall which contains damaged zone can be represented as:

$$
Q_{\text {roof }}=k_{\text {roof }} \cdot F_{\text {roof }} \cdot\left(t_{\text {int }}-t_{\text {ext }}\right) \cdot n_{\text {roof }}, W \text {. }
$$

Similarly to the $1^{\text {st }}$ variant let us assume that $Q=Q^{\prime}$, then the estimated temperature can be defined as

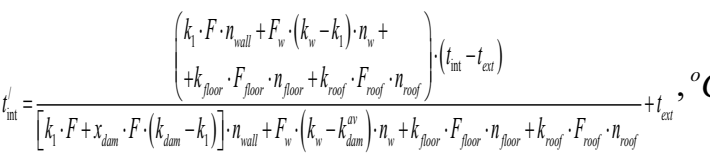

$n_{\text {wall }}, n_{w}$ - coefficient which depends on the positioning of the building envelope (wall, window) against the external air.

Expressions (10) and (15) are quite lengthy. Its obviously if we consider more building envelopes we will obtain larger expression. Therefore the previous formula can be written in general form as:

$$
t_{\text {int }}^{\prime}=\frac{Q_{\text {build }} \cdot\left(t_{\text {int }}-t_{\text {ext }}\right)}{Q_{\text {build }}^{\text {dam }}}+t_{\text {ext }},{ }^{o} \mathrm{C}
$$

$Q_{\text {build }}$ - summarized heat losses of the room enclosed by building envelopes without any damaged zone, $W$;

$Q_{\text {build }}^{\text {dam }}$ - summarized heat losses of the room enclosed by building envelopes with some damaged zone, $W$.

\section{Analysis}

The widespead in Dnipropetrovsk for the eighties of XXth century standard composition of multi-layer wall was chosen as an exemple for calculation. Figure 2 shows the cross-section of the wall.

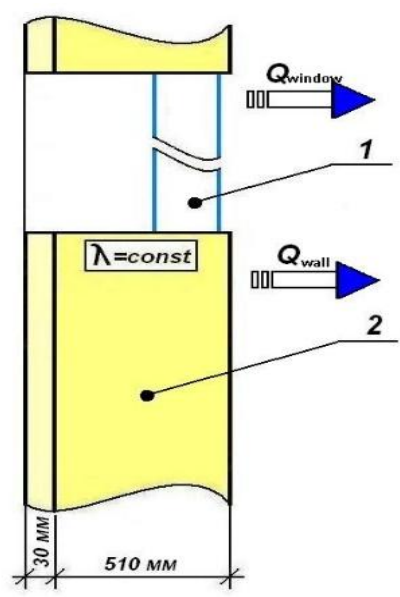

a) 


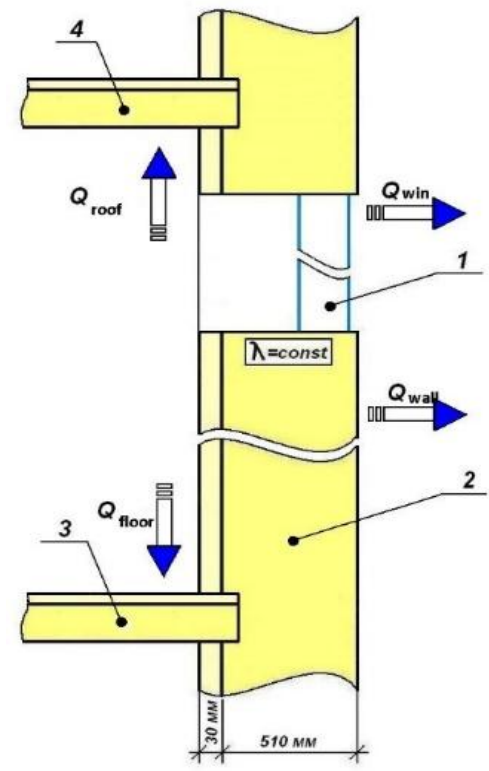

b)

Fig. 2. Variants of rooms enclosed by several different building envelopes:

a) external wall with an installed window; b) floor slab, roof slab, an external wall with an installed window.

Using (2) and (3) we can calculate the coefficient of heat transmission for the wall and thermal resistance on condition that the thickness of damaged area can take the next values $\quad \delta_{d a m}^{1}=0 \mathrm{~mm} ; \quad \delta_{d a m}^{2}=10 \mathrm{~mm}$; $\delta_{d a m}^{3}=20 \mathrm{~mm} ; \delta_{d a m}^{4}=40 \mathrm{~mm}$. The results of the calculation are shown in Table 1.

Table 1. Caracteristics of materials.

\begin{tabular}{|l|c|c|c|c|}
\hline \multirow{2}{*}{$\begin{array}{c}\text { Thermal } \\
\text { properties of the } \\
\text { external wall }\end{array}$} & \multicolumn{4}{|c|}{$\begin{array}{c}\text { Thickness of the wall containing } \\
\text { damaged area, } \mathrm{mm}\end{array}$} \\
\cline { 2 - 5 } & $\begin{array}{c}540 \\
\mathrm{~mm}\end{array}$ & $\begin{array}{c}530 \\
\mathrm{~mm}\end{array}$ & $\begin{array}{c}520 \\
\mathrm{~mm}\end{array}$ & $\begin{array}{c}510 \\
\mathrm{~mm}\end{array}$ \\
\hline $\begin{array}{c}\text { Thermal } \\
\text { resistance of the } \\
\text { wall, } \frac{m^{2} \cdot K}{W}\end{array}$ & 0,78 & 0,77 & 0,76 & 0,75 \\
\hline $\begin{array}{c}\text { Coefficient } \\
\text { heat } \\
\text { transmission, } \\
\frac{W}{m^{2} \cdot K}\end{array}$ & 1,28 & 1,30 & 1,32 & 1,34 \\
\hline
\end{tabular}

According to the obtained data, the coefficient of heat transfer and thermal resistance of the wall varies linearly [13] for $1,3 \%$ per each $10 \mathrm{~mm}$ of damaged area thickness.

Estimated inner air temperature in the room enclosed by an external wall with damaged zone and installed window was calculated using the expression (10). The results are given in Table 2 and shown on Fig. $3 a$.
Table 2. Estimation of interior airspace temperature on condition that external wall with the window encloses damaged area

\begin{tabular}{|c|l|l|l|l|}
\hline \multirow{2}{*}{$x_{\text {dam }}=\frac{F_{\text {dam }}}{F}$} & \multicolumn{4}{|c|}{ Thickness of the damaged wall, $\mathrm{mm}$} \\
\cline { 2 - 5 } & $\begin{array}{l}540 \\
\mathrm{~mm}\end{array}$ & $\begin{array}{l}530 \\
\mathrm{~mm}\end{array}$ & $\begin{array}{l}520 \\
\mathrm{~mm}\end{array}$ & $\begin{array}{l}510 \\
\mathrm{~mm}\end{array}$ \\
\hline 0 & 20,00 & 20,00 & 20,00 & 20,00 \\
\hline 0,1 & 20,00 & 19,98 & 19,97 & 19,95 \\
\hline 0,2 & 20,00 & 19,97 & 19,93 & 19,90 \\
\hline 0,3 & 20,00 & 19,95 & 19,90 & 19,85 \\
\hline 0,4 & 20,00 & 19,94 & 19,87 & 19,80 \\
\hline 0,5 & 20,00 & 19,92 & 19,84 & 19,75 \\
\hline 0,6 & 20,00 & 19,90 & 19,81 & 19,70 \\
\hline 0,7 & 20,00 & 19,89 & 19,77 & 19,66 \\
\hline 0,8 & 20,00 & 19,87 & 19,74 & 19,61 \\
\hline 0,9 & 20,00 & 19,86 & 19,71 & 19,56 \\
\hline 1 & 20,00 & 19,84 & 19,68 & 19,51 \\
\hline
\end{tabular}

Estimated inner air temperature in the room enclosed by floor slab, roof slab, an external wall with damaged zone and installed window was calculated using the expression (15). The results are given in Table 3 and shown on Fig. $3 b$.

Table 3. Estimation of interior airspace temperature on condition that investigated room is enclosed by floor slab, roof slab, external wall with damaged zone and installed window.

\begin{tabular}{|c|c|c|c|c|}
\hline \multirow{2}{*}{$x_{\text {dam }}=\frac{F_{\text {dam }}}{F}$} & \multicolumn{4}{|c|}{ Thickness of the damaged wall, $\mathrm{mm}$} \\
\cline { 2 - 5 } & $\begin{array}{c}540 \\
\mathrm{~mm}\end{array}$ & $\begin{array}{c}530 \\
\mathrm{~mm}\end{array}$ & $\begin{array}{c}520 \\
\mathrm{~mm}\end{array}$ & $\begin{array}{c}510 \\
\mathrm{~mm}\end{array}$ \\
\hline 0 & 20,00 & 20,00 & 20,00 & 20,00 \\
\hline 0,1 & 20,00 & 20,00 & 20,00 & 19,99 \\
\hline 0,2 & 20,00 & 20,00 & 19,99 & 19,99 \\
\hline 0,3 & 20,00 & 19,99 & 19,99 & 19,98 \\
\hline 0,4 & 20,00 & 19,99 & 19,98 & 19,97 \\
\hline 0,5 & 20,00 & 19,99 & 19,98 & 19,96 \\
\hline 0,6 & 20,00 & 19,99 & 19,97 & 19,96 \\
\hline 0,7 & 20,00 & 19,98 & 19,97 & 19,95 \\
\hline 0,8 & 20,00 & 19,98 & 19,96 & 19,94 \\
\hline 0,9 & 20,00 & 19,98 & 19,96 & 19,93 \\
\hline 1 & 20,00 & 19,98 & 19,95 & 19,93 \\
\hline
\end{tabular}

:

\begin{tabular}{|c|c|c|c|}
\hline 540 мм & $530 \mathrm{~mm}$ & $\begin{array}{l}20 \mathrm{MM} \\
\mathrm{ss}, \mathrm{MM}\end{array}$ & $510 \mathrm{~mm}$ \\
\hline$x=1$ & $x=0,9$ & $x=0,8$ & $x=0,7$ \\
\hline$x=0,6$ & $x=0,5$ & $x=0,4$ & $x=0,3$ \\
\hline $\mathrm{k}=0,2$ & $x=0,1$ & $x=0$ & \\
\hline
\end{tabular}




\section{品}

\begin{tabular}{llll}
540 мм & 530 мм & 520 мм & 510 мм \\
\multicolumn{5}{c}{ Thickness, } \\
x $=1$ & $x=0,9$ & $x=0,8$ & \\
$x=0,6$ & $x=0,5$ & $x=0,4$ & $x=0,3$ \\
$x=0,2$ & $x=0,1$ & $x=0$ &
\end{tabular}

b)

Fig. 3. Evaluation of indoor airspace temperature depending on the damaged area change on condition that the room is enclosed by the following building envelopes: a) external wall with damaged zone and installed window; b) floor slab, roof slab, external wall with damaged zone and installed window

Analysis of the data given in Table 2, 3 and previous results presented in [4] leads to the statement that in the case of increasing of building envelopes number (taking into account only damages of the external wall) estimated parameters are decreasing, depending on calculated (basic) temperature, by:

- $2,45 \%$ provided that the room is enclosed by external wall with an installed window;

- $0,35 \%$ on condition that the room is enclosed by floor slab, roof slab, an external wall with an installed window.

The numerical analysis was carried out by ELCUT 6.3 workbench, a program which allows calculating a three-dimensional or a two-dimensional steady-state temperature distribution and heat transfer $[15,16]$. The software is based on the finite element analysis using an appropriate grid. Properties of used materials are taken into consideration. Two basic models of rooms with various building envelopes (including damaged walls) were considered for simulations. Mentioned software allows evaluating the inner air temperature in the case of the basic variant without the damaged zone. Results are represented on the Fig. 3 a, c. Also, the variant which contains the damaged zone was investigated and the results are shown on Fig. 3 b, d.

According to the obtained results of the simulation for the both basic variants (with and without the damaged zone), we can state that there is a decreasing of the airspace temperature and the same effect was detected between the layers of building envelope. Table 4 represents temperatures on the external and inner surfaces of the building envelope and also it shows the temperature between the structural layers of the building envelope under the computer simulation. Since the data selection for the modelling was carried out in the place of the thickest damage, so we compare these data with the results of the calculations for the analogical thickness of the damaged zone from the Table 5.

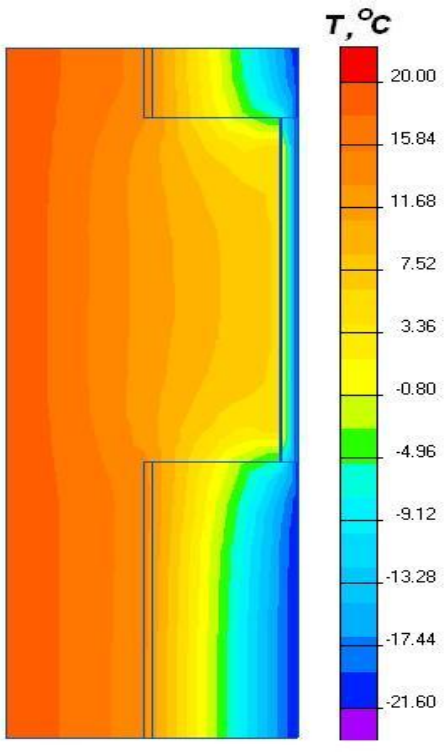

a)

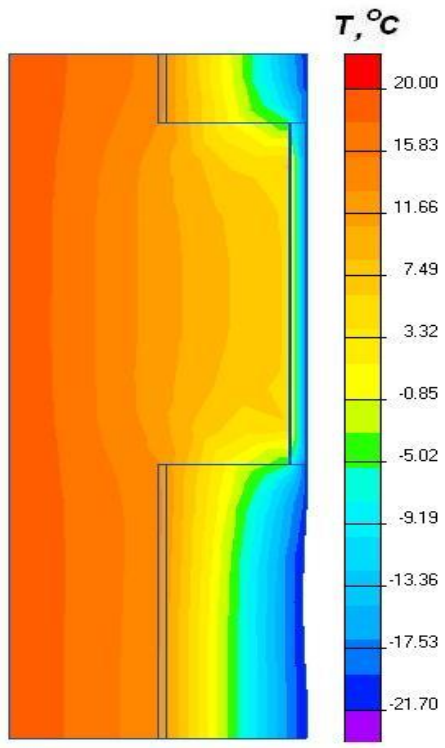

b)

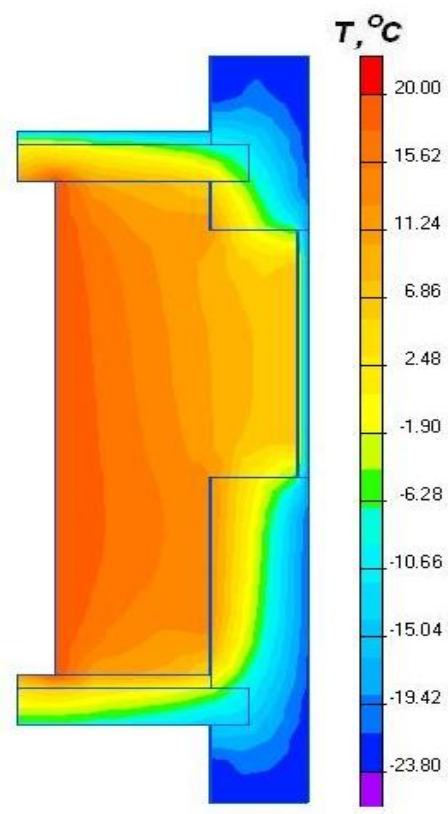

c) 


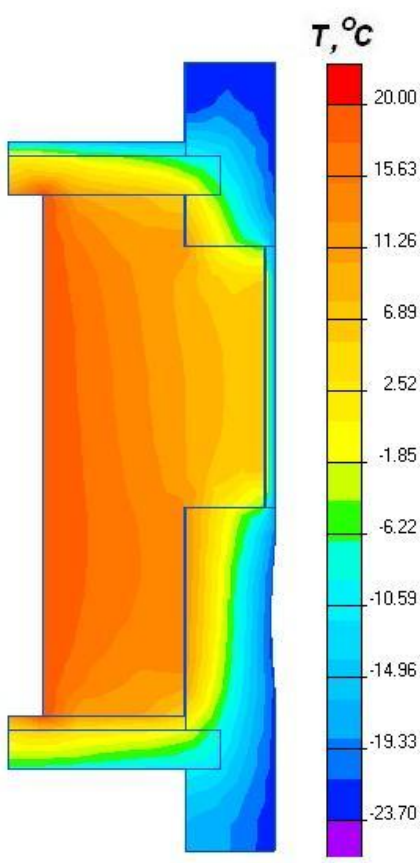

d)

Fig. 3. Modelling of the room which is enclosed by several multi-type building envelopes: a) external wall with an installed window; b) external wall which contains the damaged zone and the window; c) floor slab, roof slab, an external wall with window; d) floor slab, roof slab, an external wall with damaged zone and installed window.

Table 4. Estimated temperatures (using ELCUT 6.3) on the surfaces of the external wall layers taking into account the variation of the structural layers thickness caused by damages

\begin{tabular}{|c|c|c|c|c|}
\hline \multirow[b]{2}{*}{$\begin{array}{l}\text { Temperature } \\
\text { values on the } \\
\text { surfaces of the } \\
\text { external } \\
\text { layers }\end{array}$} & \multicolumn{4}{|c|}{$\begin{array}{l}\text { Thickness of building envelope } \\
\text { with damaged zone, } \mathrm{mm}\end{array}$} \\
\hline & $\begin{array}{l}\text { Variant } \\
\text { of Fig. } \\
3 \mathrm{a} \\
(540 \\
\mathrm{mm}) \\
\end{array}$ & $\begin{array}{l}\text { Variant } \\
\text { of Fig. } \\
3 \mathrm{~b} \\
(510 \\
m m) \\
\end{array}$ & $\begin{array}{l}\text { Variant } \\
\text { of Fig. } \\
3 \mathrm{c} \\
(540 \\
m m) \\
\end{array}$ & $\begin{array}{l}\text { Variant } \\
\text { of Fig. } \\
3 \mathrm{~d} \\
(510 \\
m m) \\
\end{array}$ \\
\hline $\begin{array}{l}\text { Temperature on } \\
\text { the inner surface } \\
\text { of the wall, } \\
\tau_{\text {int }}^{/ /}{ }^{o} C\end{array}$ & 13,95 & 13,72 & 13,49 & 13,26 \\
\hline $\begin{array}{l}\text { Temperature } \\
\text { between } \\
\text { structural layers } \\
\text { of the wall, } \\
\tau_{1}^{\prime \prime},{ }^{o} C\end{array}$ & 11,81 & 11,68 & 12,42 & 12,23 \\
\hline $\begin{array}{l}\text { Temperature on } \\
\text { the external } \\
\text { surface of the } \\
\text { wall, } \tau_{\text {ext }}^{\prime \prime},{ }^{o} \mathrm{C}\end{array}$ & $-21,5$ & $-21,33$ & $-21,35$ & $-21,06$ \\
\hline
\end{tabular}

Table 5. Estimated temperatures on the surfaces of the external wall layers taking into account the variation of the structural layers thickness caused by damages.

\begin{tabular}{|l|c|c|}
\hline \multirow{2}{*}{$\begin{array}{l}\text { Temperature values on the } \\
\text { surfaces of the external wall } \\
\text { layers }\end{array}$} & $\begin{array}{l}\text { Thickness of the } \\
\text { building envelope with } \\
\text { damaged zone, } \mathrm{mm}\end{array}$ \\
\cline { 2 - 3 } & $540 \mathrm{~mm}$ & $510 \mathrm{~mm}$ \\
\hline $\begin{array}{l}\text { Temperature on the inner } \\
\text { surface of the wall, } \tau_{\text {int }}^{\prime},{ }^{o} \mathrm{C}\end{array}$ & 13,68 & 13,39 \\
\hline $\begin{array}{l}\text { Temperature between } \\
\text { structural layers of the wall, } \\
\tau_{1}^{\prime},{ }^{o} \mathrm{C}\end{array}$ & 11,64 & 11,25 \\
\hline $\begin{array}{l}\text { Temperature on the external } \\
\text { surface of the wall, } \tau^{\prime}{ }^{\prime}{ }^{o}{ }^{o} \mathrm{C}\end{array}$ & $-20,61$ & $-22,48$ \\
\hline
\end{tabular}

The results represented in Table 4 and 5 are compared in Table 6.

Table 6. Part of divergence between the calculated results and the temperature values obtained using ELCUT 6.3

\begin{tabular}{|c|c|c|c|c|}
\hline \multirow[b]{2}{*}{$\begin{array}{l}\text { Temperature } \\
\text { values on the } \\
\text { surfaces of the } \\
\text { external wall } \\
\text { layers }\end{array}$} & \multicolumn{4}{|c|}{$\%$ of divergence } \\
\hline & $\begin{array}{l}\text { Varian } \\
\text { t of } \\
\text { Fig. } 3 \mathrm{a} \\
(540 \\
\mathrm{mm})\end{array}$ & $\begin{array}{l}\text { Varian } \\
\mathrm{t} \text { of } \\
\text { Fig. } 3 \mathrm{~b} \\
(510 \\
\mathrm{mm})\end{array}$ & $\begin{array}{l}\text { Varian } \\
\mathrm{t} \text { of } \\
\text { Fig. } 3 \mathrm{c} \\
(540 \\
\mathrm{mm})\end{array}$ & $\begin{array}{l}\text { Varian } \\
\text { t of } \\
\text { Fig. } 3 \mathrm{~d} \\
(510 \\
\mathrm{mm})\end{array}$ \\
\hline $\begin{array}{l}\text { Temperature on } \\
\text { the inner surface } \\
\text { of the wall, } \\
\tau_{\text {int }}^{\prime},{ }^{o} C\end{array}$ & 1,9 & 2,4 & 1,4 & 0,9 \\
\hline $\begin{array}{l}\text { Temperature } \\
\text { between } \\
\text { structural layers } \\
\text { of the wall, } \\
\tau_{1}^{\prime},{ }^{o} C\end{array}$ & 1,4 & 3,7 & 6,3 & 8,0 \\
\hline $\begin{array}{l}\text { Temperature on } \\
\text { the external } \\
\text { surface of the } \\
\text { wall, } \tau_{308}^{\prime},{ }^{o} \mathrm{C}\end{array}$ & 4,1 & 5,4 & 3,5 & 6,7 \\
\hline
\end{tabular}

The calculated temperature values on the inner surface of the wall differ from the results of modelling by $2,4 \%$. This result doesn't exceed the tolerance.

The divergence of calculated results and computer modelling data (ELCUT 6.3) can be explained by the following:

- in case of two-dimensional simulation we don't take into account the part of damaged zone on the surface of plane wall $x_{d a m}$;

- in the case of mathematical modelling we take into account equal thickness for the building envelope in 
damaged zone, whereas in the case of computer modelling mentioned parameter is varying.

\section{Conclusions}

This paper is devoted to the analytical investigation (for climite conditions of Dnipropetrovsk) of indoor airspace temperature variation provided that the room is enclosed by several multi-type building envelopes and one of them contains damaged zones. The obtained data reveals that the presence of damaged zones leads to decrease of temperature values at the border of each wall layer, therefore we observe the drop of indoor airspace temperature.

Taking into consideration the results presented in [4] we can state that in the case of increasing of building envelopes number (taking into account only damages of the external wall) estimated parameters are decreasing, depending on calculated (basic) temperature, by:

- $2,45 \%$ provided that the room is enclosed by external wall with an installed window;

- $0,35 \%$ on condition that the room is enclosed by floor slab, roof slab, an external wall with an installed window.

Results of mathematical and computer modelling (ELCUT 6.3) let us assume that its possible to evaluate the temperature change on external and inner surfaces of the building envelope and the temperature between layers on condition that the part of damaged zone on the surface of the plane wall $x_{d a m}$ is taken into account.

\section{References}

1. K.F. Fokin, Heat transfer through the building envelope. - 5-th ed-256, (Moscow, 2006)

2. Building standard of Ukraine. ДСТУ Б В.2.6101:2010 Methodes of thermal resistance determination for building envelopes. 84 p., (Kiev: Ministry of Con-s and Archit-re of Ukraine, 2010)

3. I. A. Kolesnik, V. O. Petrenko, I. L. Vetvitskiy, D. A. Vetvitskaya, Analysis of the influence of the thermal characteristics of window units on the microclimate conditions in the heating season. Const. Mat. Sc. Mec. Eng. 92. - P. 67-73, (2016)

4. I. V. Golyakova, V. O. Petrenko, S. Z. Polischuk, A. S. Belikov, A. O. Petrenko, E. G. Kushnir, Microclimate in rooms with local heat dissipation. 120 p. (2016)

5. D. O. Lapshina, Elaboration of energy saving and ecological means of microclimate normalization in chambers of mines with heat sources E. E. M. of Ad. T. 2 (10). - P. 32-39. (2016)

6. V. A. Pashynsky, O. A. Plotnikov, The methodology of the probable estimating of temperature regime of the walls Collection of sc. works of the Uk. State Ac. of Rail. Trans. 148 (2). P. 138-143. (2014)

7. V. V. Cherniavsky, A. M. Pashchenko, O. B. Borisenko, R. V. Lopatkov, Analysis of the cracking of the decorative-plaster layer of the facade system depending on the temperature and humidity of the external air, Coll. of Sc. W. of PNTU Y. Kondratyuk]: Sectoral engineering, construction. - 2010 2. - P. 147-151.

8. V. I. Deshko, N. A. Buyk Influence of thermal protection of the building on parameters of thermal comfort Collection of sc. works of the Uk. State Ac. of Rail. Trans. 153. - P. 121-128. (2015)

9. K. Dikarev, A. Berezyuk, O. Kuzmenko, and A. Skokova, Experimental and Numerical Thermal Analysis of Joint Connection «Floor Slab Balcony Slabe» with Integrated Thermal Break, En. Pr., 85, pp. 184-192, (2016)

10. E. Zavadskas, S. Raslanas, A. Kaklauskas, The selection of effective retrofit scenarios for panel houses in urban neighborhoods based on expected energy savings and increase in market value: The Vilnius case, En. and Build. 4. - P. 573-587. (2008)

11. M. Bojic, A. P. Parvedy, H. Boyer, Optimization of thermal comfort in building through envelope design. Int. Conf. ECOS 2012, pp.1-10, (2012)

12. V. O. Petrenko, A. O. Petrenko, I. V. Golyakova, Factors that affect the microclimate in the room, which has defects of the enclosing structures and OVEC systems Const. Mat. Sc. Mec. Eng. 93. - P. 286-291, (2016)

13. V. Petrenko, K. Dikarev, A. Skokova, O. Kuzmenko, Estimation of indoor temperatures on condition that building envelope is damaged Rev. Rom. De ing. Civ. 1. - P. 36-44, (2017)

14. SNiP 2.04.05-91 Heating, ventilation and air conditioning. Moscow: Stroiizdat, - 342 p., (1991)

15. L.V. Zinevich. Solution of construction tasks using ELCUT software package Coll. of Sc. W. of the XIV intern. Interuniv. Sc.-pr. Conf. of Y. Sc., D. St. and Post-grad. St. - Moscow: MSSU. 864p. (2011)

16. A.I. Mishichev, A.E. Martyanova. Solution of heat conduction problems by the finite element method in the CAE-system ELCUT: Methodical instructions for studying CAD courses. - Astrakhan: ASTU, - 39 p., (2001)

17. O. T. Voznyak, Influence of indoor climate parameters on human heat exchange Bull. of the Nat. Univ. "Lv. Polytech." 662: Th. and Pract. of Const. - P. 84-88, (2010)

18. Estimated parameters of the microclimate of premises for designing and estimating of energy characteristics of buildings in relation to air quality, heat comfort, lighting and acoustics of buildings (EN 15251: 2007, IDT): DSTU B EN 15251: 2011. K .: - Minregion of Ukraine. - 33 p., (2012).

19. EN ISO 7730 European Standart. Moderate thermal environments- Determination of the PMV and PPD indices and specification of the conditions for the thermal comfort. CEN, (1995)

20. Ergonomics of the thermal environment. Analytical definition and interpretation of thermal comfort on the basis of calculation of PMV and PPD indices and criteria of local thermal comfort (EN ISO 7730: 2011, IDT): DSTU B EN ISO 7730: 2011- K $\therefore$ - Minregion of Ukraine, - 64 p., (2012). 